\title{
Aspheric Refractive Correction of Irregular Astimatism
}

\author{
Massimo Camellin ${ }^{1}$ and Samuel Arba-Mosquera 2,3 \\ 1SEKAL Rovigo Microsurgery Centre, Rovigo, \\ ${ }^{2}$ Grupo de Investigación de Cirugía Refractiva y Calidad de Visión, Instituto de \\ Oftalmobiología Aplicada, University of Valladolid, Valladolid, \\ ${ }^{3}$ SCHWIND eye-tech-solutions, Kleinostheim, \\ ${ }^{1}$ Italy \\ ${ }^{2}$ Spain \\ ${ }^{3}$ Germany
}

\section{Introduction}

In irregular astigmatism, the two meridians may be located at something other than 90 degrees apart (principal meridians are not perpendicular); or there are more than two meridians.

Irregular astigmatism is that in which the curvature varies in different parts of the same meridian or in which refraction in successive meridians differs irregularly. Irregular astigmatism is associated with loss of vision.

Irregular astigmatism occurs when the orientation of the principal meridians changes from one point to another across the pupil, or when the amount of astigmatism changes from one point to another.

The further distinction of irregular astigmatism includes regularly or irregularly irregular astigmatism and relates to the presence of pattern recognition on computerized topography. Irregularly irregular astigmatism is rough or uneven, and shows no recognizable pattern on topography.

Irregular astigmatism with defined pattern (macroirregular, or regularly irregular astigmatism) in which there is a steep or flat area of at least $2 \mathrm{~mm}$ of diameter, which is the primary cause of the astigmatism.

Irregular astigmatism with undefined pattern (microirregular, or irregularly irregular astigmatism) in which multiple irregularities; big and small, steep and flat, and profile maps are almost impossible to calculate.

Irregular astigmatism may appear in irregular but stable corneas (e.g., irregular scar surface), in which, cornea is irregular because of local geography, or in irregular but unstable corneas (biomechanical decompensation), in which, cornea is irregular because of global corneal weakness.

The astigmatism we will refer during this chapter is corneal astigmatism. In particular we will analyse corneal astigmatism and the effects on and influences from:

1. Aspheric Optical Zones and The Effective Optical Zone 
2. Correction of aberrations and refractive errors in irregular astigmatism

3. TransPRK

4. Corneal Wavefront Epi-LASEK

5. Pathologic TransPRK

\section{Aspheric Optical Zones and the Effective Optical Zone}

The required ablation depth in corneal laser refractive surgery increases with the amount of ametropia to be corrected and the diameter of the optical zone selected ${ }^{1}$. Therefore, the smallest diameter optical zone should be used compatible with normal physiologic optics of the cornea ${ }^{2}$.

Complaints of ghosting, blur, haloes, glare, decreased contrast sensitivity, and vision disturbance ${ }^{3}, 4$ have been documented with small optical zones, especially when the scotopic pupil dilates beyond the diameter of the surgical optical zone 5 , and these symptoms may be a source of less patient satisfaction ${ }^{6}$. This is supported by clinical findings on night vision with small ablation diameters 7,8 as well as large pupil sizes ${ }^{5}, 8$ and attempted correction 9.

Laser refractive surgery generally reduces low order aberrations (defocus and astigmatism), yet high-order aberrations, particularly coma and spherical aberration, may be significantly induced 10,11 .

In recent years, the increasing the size of the planned ablation zone and the use of new techniques to measure aberrations ${ }^{12}$ opened the possibility to correct, or at least reduce the induction, some of the high-order aberrations. Excimer laser refractive surgery has evolved from simple myopic ablations to the most sophisticated topography-guided ${ }^{13}$ and wavefront-driven ${ }^{14}$, either using wavefront measurements of the whole eye (obtained, e.g., by Hartmann-Shack wavefront sensors) or by using corneal topography-derived wavefront analyses 15,16 , customised ablation patterns. Special ablation patterns were designed to preserve the preoperative level of high-order aberrations $17,18,19$, if the best corrected visual acuity, in this patient, has been unaffected by the pre-existing aberrations ${ }^{20}$. Thus to compensate for the aberrations induction observed with other types of profile definitions ${ }^{21}$, some of those sources of aberrations are those ones related to the loss of efficiency of the laser ablation for non-normal incidence $22,23,24$.

Methods for determining functional optical zones have been used previously. Independently developed ray-tracing programs ${ }^{8},{ }^{25}$ have been used to determined Functional Optical Zone after refractive surgery. A direct approach to measure Functional Optical Zone after refractive surgery has been proposed by manually determining the transition region between treated and untreated areas from corneal topography maps ${ }^{26}$.

Fig. 1 shows what it can be considered an intuitive definition of the optical zone for both myopic and hyperopic treatments. The actual definition of the optical zone reads "the part of the corneal ablation area that receives the full intended refractive correction" (Drum B. The Evolution of the Optical Zone in Corneal Refractive Surgery. 8th International Wavefront Congress, Santa Fe, USA; February 2007). However, operational definition of the Optical Zone consists of the part of the corneal ablation area that receives the treatment that is designed to produce the full intended refractive correction. Finally, Effective Optical Zone can be defined as the part of the corneal ablation area that actually conforms to the theoretical definition. However, the definition implies that the optical zone need not be circular. 


\section{How to measure the Optical Zone? \\ SCHWIND \\ aye-toch-solutions}
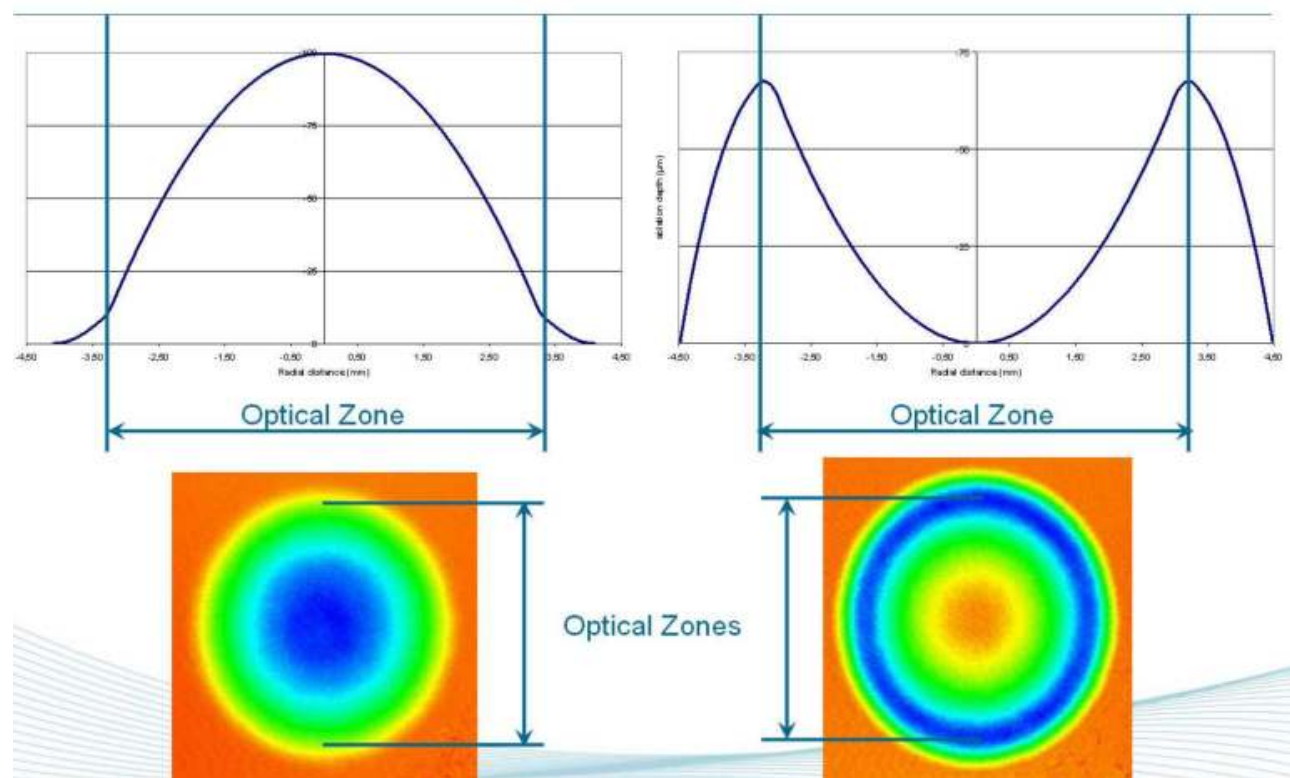

Optical Zones

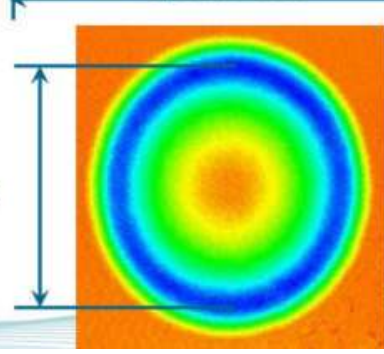

Fig. 1. Intuitive definition of the optical zone.

In order the analyse Effective Optical Zone in our treatments in a systematic way consistent with formal definitions, we decided to base our analysis upon previous knowledge. Since wavefront aberration describes properly optical quality, it seems adequate to use wavefront aberration for determining Effective Optical Zone. Since we were applying the analysis to corneal laser refractive surgery, it seems adequate to use corneal wavefront aberration for determining Effective Optical Zone. Since corneal refractive surgery increases wavefront aberration, it seems adequate to analyse the change of the corneal root-mean-square (RMS) for determining Effective Optical Zone. Since the most induced term is spherical aberration, it seems adequate to analyse the change of the corneal spherical aberration for determining Effective Optical Zone. Since AMARIS Aberration-Free profiles aim being neutral for High order aberration, it seems adequate to analyse the root-mean-square of the change of the corneal wavefront aberration for determining Effective Optical Zone.

The measurement technique actually imposes restrictions on optical zone size that may underestimate it for decentrations. On the other hand, data not fit by the Zernike polynomials up to the seventh radial order (36 Zernike coefficients). It is known that the residual irregularity of the cornea not fit by Zernike's may have a significant impact on visual quality. Ignoring this effect might bias the effective optical zone size determined leading to an overestimate that can be significant.

Uozato and Guyton ${ }^{2}$ were the first to calculate the optical zone area needed to obtain glarefree distance vision in emmetropia. They stated that, "for a patient to have a zone of glare- 


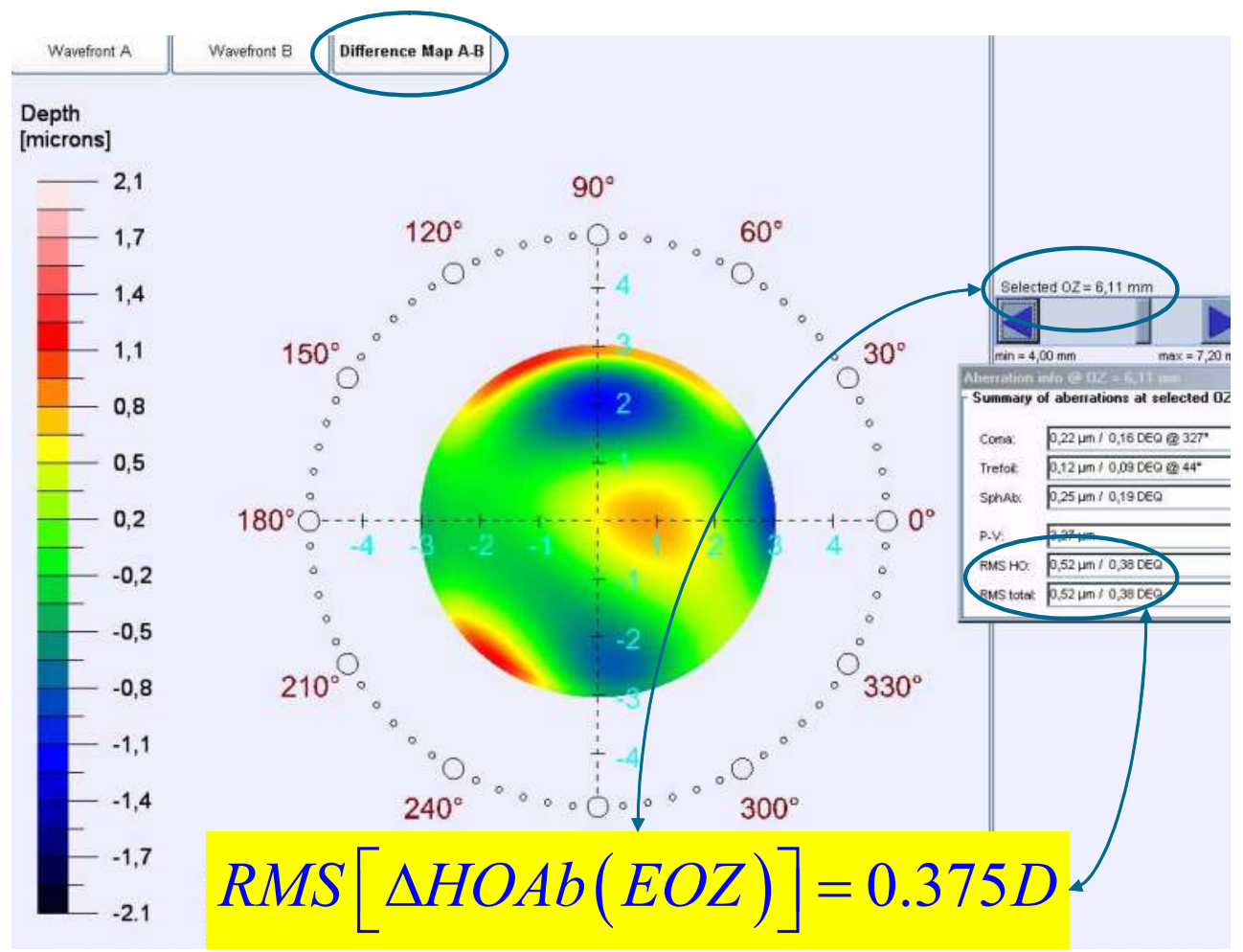

Fig. 2. Formal definition of the functional optical zone.

free vision centered on the point of fixation, the optical zone of the cornea must be larger than the entrance pupil (apparent diameter of the pupil)." Not only must this optical zone be without scarring and irregularity, but it must also be of uniform refractive power.

Biomechanical changes after Myopic Astigmatism treatments contribute to an oblate contour, increasing spherical aberration and shrinking the effective optical zone. Healing response ${ }^{27}$, radial ablation efficiency $\operatorname{losses}^{28}$ and biomechanical effects ${ }^{29}$ all reduce the effective ablation in the outer portion of the nominal optical zone. These effects shrink the actual zone of full refractive correction, i.e., the effective optical zone. They also distort attempted cylindrical ablations by flattening the cornea along the astigmatic axis, introducing an unintended spherical correction component and reducing the cylindrical correction.

The shrinking effect is larger for major corrections, i.e. larger optical zones should be used for major corrections, but larger optical zones result in deeper and longer ablations increasing the potential risks of keratectasia $30,31$.

A similar approach was used by Tabernero et al.32, applied in a different way. They analysed directly on the cornea the functional optical zone in patients pre and postoperatively, instead applied to the differential map. They wanted to determine the Functional Optical Zone of the cornea, whereas we aimed to determine the Effective Optical Zone of the treatments. But essentially the methods are equivalent. 
Maloney ${ }^{5}$ described the consequences of a decentered optical zone and discussed methods to ensure centering.

Effective Optical Zone correlates positively with Planned Optical Zone, declines steadily with increasing Defocus corrections; and Effective Optical Zone depends strongerly on Planned Optical Zone than on Spherical equivalent.

On average, and simplifying the relationship to only Effective Optical Zone and Planned Optical Zone we observed that Planned Optical Zone larger than $6.75 \mathrm{~mm}$ result in Effective Optical Zone, at least, as large as Planned Optical Zone. For Optical Zone smaller than 6.75 $\mathrm{mm}$, a nomogram for Optical Zone can be applied.

Mok and Lee $^{33}$ reported that larger optical zones decrease postoperative high-order aberrations. They found the measured high-order aberrations to be less in eyes with larger optical zones. Assessing the quality of vision (rather than the quality of the optical zone) after a refractive procedure is a separate issue. The relationship between pupil size and vision after refractive surgery is critically important and this relationship cannot be evaluated accurately with a measurement of aberrations through a predetermined aperture with an aberrometer. Pupil sizes vary considerably among patients depending on light level and age ${ }^{34}$. Mok and Lee have shown a strategy for planning optical zone size based on patient pupil size. However, an aberration analysis that takes into account variations in planned optical zone size may provide more insight as to the quality of the outcome obtained.

Partal and Manche ${ }^{35}$ using direct topographic readings observed over a large sample of eyes in moderate compound myopic astigmatism, a reduction from Planned Optical Zone of 6.50$\mathrm{mm}$ to Effective Optical Zone of $6.00-\mathrm{mm}$. Noteworthy and opposed to our findings, they did not find a greater contraction of Effective Optical Zone for increasing myopic corrections.

Qazi et al. ${ }^{36}$ using a different approach observed over a sample of eyes similar to ours, a reduction from Planned Optical Zone of 6.50-mm to Effective Optical Zone of 5.61-mm.

To extend our methodology for the analysis of customised corrections can be quite simple if we consider that customised corrections in their intrinsic nature aim to reduce aberrations (either from the corna only, or from the complete ocular system) to a zero level. In this way, the corresponding formulations would be:

$$
\begin{aligned}
& R M S h o_{C W}(E O Z)=0.3 D \\
& R M S h o_{O W}(E O Z)=0.3 D
\end{aligned}
$$

for corneal $(\mathrm{CW})$ and ocular wavefront $(\mathrm{OW})$ corrections respectively.

It is possible that the Effective Optical Zone could be larger than the Planned Optical Zone if it encompasses some portions of the Transition Zone, or even larger than the Total Ablation Zone. Although Planned Optical Zone, Transition Zone, and Total Ablation Zone are parameters defined by the laser treatment algorithms, Effective Optical Zone must be determined postoperatively (from the differences to the baseline) and may change with time because of healing and biomechanical effects. In the same way, it would be possible that the Functional Optical Zone were larger postoperatively than it was preoperatively, or that the Functional Optical Zone could be larger than the Planned Optical Zone or even than the Total Ablation Zone. 
For our analysis, the concept of equivalent defocus (DEQ) has been used as a metric to minimise the differences in the Zernike coefficients due to different pupil sizes. Seiler et al. ${ }^{37}$ described an increase in spherical aberration with pupil dilation in corneas that have undergone photorefractive keratectomy but not in healthy corneas.

In conclusion, wavefront aberration can be a useful metric for the analysis of the effective optical zones of refractive treatments or for the analysis of functional optical zones of the cornea or the entire eye by setting appropriate limit values. In particular, the method seems to be a rigorous analysis accounting for any deviation from the attempted target for the wavefront aberration.

The profiles etched onto the cornea and their optical influence greatly differ between myopic and hyperopic corrections ${ }^{38,39}$. Biomechanical changes after Hyperopic Astigmatism treatments contribute to a hyperprolate contour, decreasing spherical aberration to negative values, and shrinking the effective optical zone. In our own experience (data submitted for publication), comparing Effective Optical Zone in myopic and hyperopic astigmatism, we observed that Effective Optical Zone is significantly smaller in hyperopic astigmatism compared to myopic astigmatism. In myopic astigmatism, we observed a mean Effective Optical Zone of 6.74-mm analyzed with the RMSho method and 6.42-mm analyzed with the RMS(HOAb) method, whereas in hyperopic astigmatism the values were $6.47-\mathrm{mm}$ for the RMSho method and $5.67-\mathrm{mm}$ analyzed with the RMS(HOAb) method. The mean relative ratio between Effective Optical Zone and Planned Optical Zone diameters was $0.97 \pm 0.06$ for myopia and $0.90 \pm 0.12$ for hyperopia, whereas the mean relative ratio between Effective Optical Zone and Planned Optical Zone surfaces was $0.95 \pm 0.12$ for myopia and $0.81 \pm 0.26$ for hyperopia. Determined Effective Optical Zone for hyperopic astigmatism were more scattered than the ones for myopic astigmatism. For equivalent corrections, mean Effective Optical Zone were smaller for hyperopia than for myopia by $-8 \% \pm 8 \%$ in diameter, or by $-15 \% \pm 13 \%$ in surface. As well, the impact of the defocus correction in reducing the size of the Effective Optical Zone is much stronger in hyperopia than in myopia.

For our analysis the threshold value of $0.3 \mathrm{D}$ for determining Effective Optical Zone was arbitrarily chosen, since with simple spherical error, degradation of resolution begins for most people with errors of $0.3 \mathrm{D}$. If other value was used, the general conclusions derived in this study will still hold. However, the numerical values can be a bit larger for threshold values larger than $0.3 \mathrm{D}$, and smaller for values below $0.3 \mathrm{D}$. We have actually re-run the analyses for $0.2 \mathrm{D}$ and $0.5 \mathrm{D}$ thresholds, and found $-18 \%$ smaller Effective Optical Zone and $+10 \%$ larger Effective Optical Zone respectively.

Our search algorithm is an "increasing diameter" analysis, this ensures that the smallest Effective Optical Zone condition is found. Finally, our search was set to start from 4-mm upwards, i.e. $3.99 \mathrm{~mm}$ is the smallest Effective Optical Zone that could be found. We have done that because for very small analysis diameters, the Zernike fit seems to be less robust, mostly due to the decreasing sampling density within the unit circle.

The magnitude of astigmatism corrected could affect the diameter at which the EQ of RMSho is greater than $0.375 \mathrm{D}$. For example, an eye with $1 \mathrm{DS} /+3 \mathrm{D}$ of hyperopia vs. $2.5 \mathrm{D}$ of hyperopia would have different Effective Optical Zone and Functional Optical Zones based on the definitions, despite the same SE.

Although it is generally accepted and well known that the effective optical zone diameter is less than the intended optical zone diameter, the specific results in this study are possibly 
only relevant for patients operated with the actual specific excimer laser and software. In the event of wavefront-guided treatments, results may differ.

This study was focused on corneal aberrations, but the optical quality of the post-operative eyes depends on aberrations in the whole eye. We are confident that the conclusions will still hold when ocular aberrations are considered for the analysis.

\section{Correction of aberrations and refractive errors in irregular astigmatism}

At the SEKAL Micro Chirurgia in Rovigo, we basically perform surface treatments in the form of LASEK ${ }^{40}$ or Epi-LASEK ${ }^{41}$ techniques $^{42}$. These in combination with the SCHWIND AMARIS offer advantages particularly in the high safety of these methods because no preparation of a corneal flap takes place, thus no enduring weakening of the cornea, and the demonstrated accuracy of the AMARIS treatments, as well as the efficient control over corneal aberrations. The treatments are in nearly every case painless. Quality of vision is restored within 10 days and remains stable over the long-term.

- Specific compensation for different biomechanical effects in the different techniques

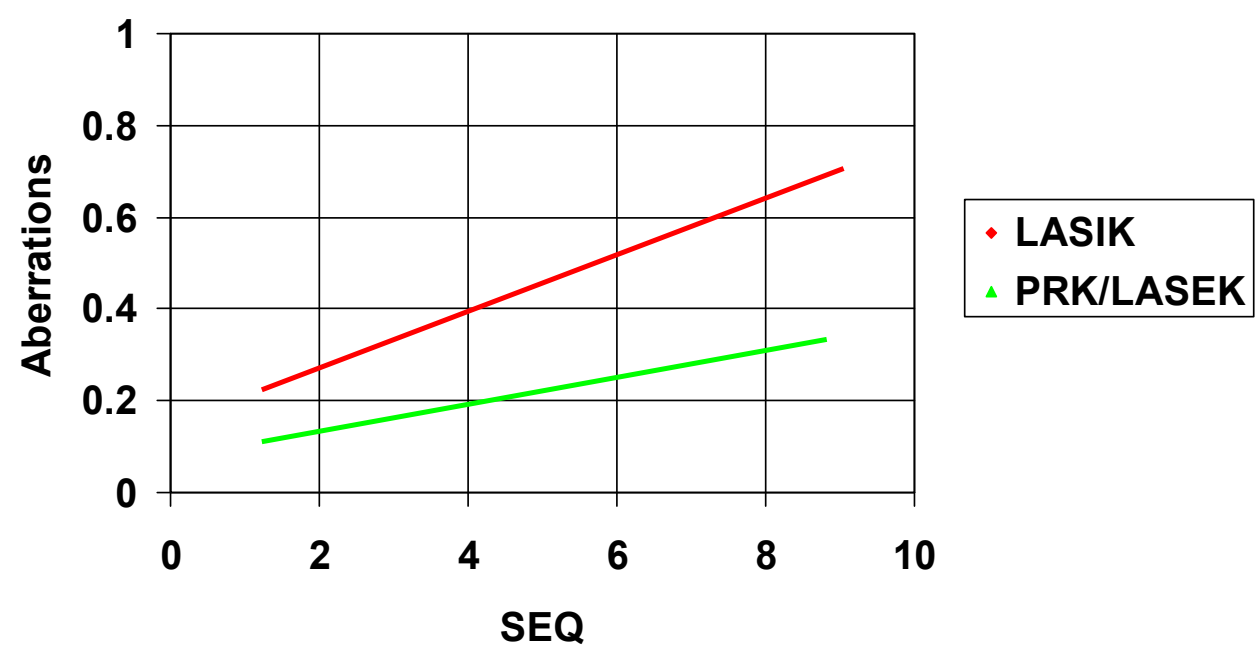

Fig. 3. Classic induction of aberration may differ between stromal and surface ablations.

Fig. 3 shows the modelled induction of aberration observed clinically using Munnerlyn based ablation profiles. It can be seen, that this induction of aberrations may differ between stromal and surface ablations in a relevant way. The origins of these differences is probably multifold: The creation of a corneal flap weakens the corneal structure prior to the ablation, so that by the creation of this flap (irrespective with the technique with which it is created) may induced optical alterations of the cornea. Further, the ablation takes place at different corneal depths (more superficially in PRK and deeper in LASIK). Since the cornea is structured in well organized layers, but each layer has its own entity and layers differ their 
composition in depth, it may be inferred that different aberrations and aberration patterns may be induced. Taking this into account, specific compensation for different biomechanical effects in the different techniques shall be considered and implemented in the treatment devices.

\subsection{Centration aids}

Mainly, two different centration references can be detected easily and measured with currently available technologies. Pupil centre may be the most extensively used centration method for several reasons. First, the pupil boundaries are the standard references observed by the eye-tracking devices. Moreover, the entrance pupil can be well represented by a circular or oval aperture, and these are the most common ablation areas. Centering on the pupil offers the opportunity to minimize the optical zone size. The pupil centre considered for a patient who fixates properly defines the line-of-sight, which is the reference axis recommended by the Optical Society of America for representing the wavefront aberration.

The corneal vertex in different modalities is the other major choice as the centration reference. In perfectly acquired topography, if the human optical system were truly coaxial, the corneal vertex would represent the corneal intercept of the visual axis. Despite the human optical system is not truly coaxial, the cornea is the main refractive surface. Thus, the corneal vertex represents a stable preferable morphologic reference. Ablations can be centered using the pupillary offset, the distance between the pupil centre and the normal corneal vertex, which corresponds to the angle between the line of sight and the visual axis.

For aspherical, or, in general, non-wavefront-guided treatments, in which the minimum patient data set (sphere, cylinder, and axis values) from the diagnosis is used, it is assumed that the patient's optical system is aberration-free or that those aberrations are not clinically relevant (otherwise a wavefront-guided treatment would have been planned). For those reasons, the most appropriate centering reference is the corneal vertex; modifying the corneal asphericity with an ablation profile neutral for aberrations, including loss of efficiency compensations. For wavefront-guided treatments, change in aberrations according to diagnosis measurements, a more comprehensive data set from the patient diagnosis is used, including the aberrations, because the aberrations maps are described for a reference system in the centre of the entrance pupil. The most appropriate centering reference is the entrance pupil as measured in the diagnosis.

Due to the smaller angle kappa associated with myopes compared with hyperopes, centration issues are less apparent ${ }^{43}$. However, angle kappa in myopes may be sufficiently large to show differences in results. A pupillary offset of 0.25 millimeters seems to be sufficiently large to be responsible for differences in aberrations.

We prefer using aberration-free treatments centred in the pupil in cases where the pupil centre differs less than $0.1 \mathrm{~mm}$ from the corneal vertex, and aberration-free treatments centred in the corneal vertex in cases where the pupil centre differs more than $0.1 \mathrm{~mm}$ and less than $0.5 \mathrm{~mm}$ from the corneal vertex.

We prefer using corneal wavefront for hyperopia in combination with astigmatism in cases where the pupil centre differs more than $0.5 \mathrm{~mm}$ from the centre of the astigmatism (= corneal vertex). 


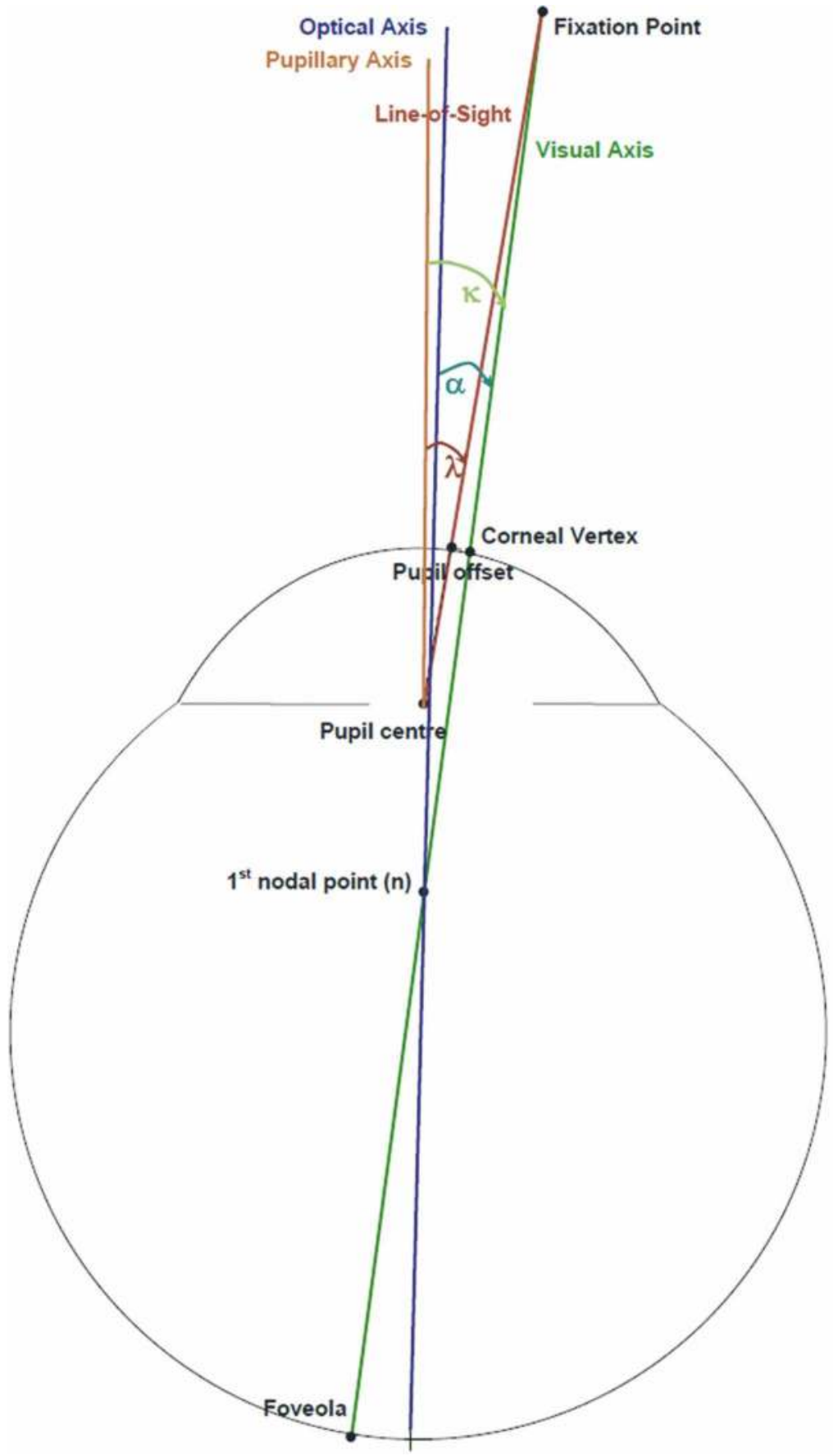

Fig. 4. Principal reference axes of the human eye. 
In this way, results and centration are improved.

\subsection{Optical zone}

Another important point for the control of aberrations is the appropriate selection of the optical zone. The use of large optical zones (with smart blending zones) (to avoid edge effects, especially in coma and spherical aberration) shall be considered.

In general, optical zone size shall be at least the size of the scotopic pupil diameter plus twice the pupil-vertex offset plus the eye-tracker resolution.

The optical zone should normally be at least $7 \mathrm{~mm}$ and correspond with the mesopic pupil diameter; we never go below $6.5 \mathrm{~mm}$. In hyperopia, an optical zone of $7.5 \mathrm{~mm}$ is preferred in order to minimize the risk of regression and possible halos at night. In hyperopia, we never go below $7 \mathrm{~mm}$. Whenever necessary, we protect the hinge with a spatula.

Differences between effective optical zone and planned optical zone are larger for smaller planned optical zone or larger corrections ${ }^{44}$. Planned optical zones $>6.75 \mathrm{~mm}$ result in effective optical zones at least as large as planned optical zones. For optical zones $<6.75 \mathrm{~mm}$, a nomogram should be applied.

\subsection{Epi-LASEK technique}

The only difference in the Epi-LASEK technique compared with LASEK is the use of an epikeratome (nasal hinge) for separation of the epithelium. This is our preferred technique because the epithelium is easily separated, excellent hinge width is achieved and putting the epithelium back in place is easier than with LASEK or Epi-LASIK.

We use to apply LASEK for myopia up to $-3 \mathrm{D}$, and Epi-LASEK for myopia up to $-12 \mathrm{D}$, hyperopia up to $+5 \mathrm{D}$, or astigmatism up to $-6 \mathrm{D}$. The use of mitomycin $\mathrm{C}$ significantly decreases subepithelial haze ${ }^{45}$.

If the pupil can get larger than $8 \mathrm{~mm}$, we place a limit on the treatment spectrum of -4 to $+1.5 \mathrm{D}$.

In myopia, a central residual corneal thickness of at least $350 \mu$ m including the epithelium must be considered. In hyperopia, the peripheral residual stromal thickness shall remain thicker than in the center.

The postoperative corneal curvature should be $\geq 32 \mathrm{D}$ to ensure achievement of good vision quality. Additionally, the postoperative corneal curvature should be around $49 \mathrm{D}$, on the other side pay attention to preoperative very flat corneas (i.e. 40-42 D), because there might be a bad peripheral transition in case of high corrections (i.e. a significant step).

Following this rules, in a series of 20 consecutive patients treated for myopic astigmatism, we merely want to outline that both, the Spherical equivalent and the cylinder were significantly reduced to subclinical values at six months postoperatively (mean residual defocus refraction was $-0.05 \pm 0.43 \mathrm{D}$ (range -1.00 to $+0.62 \mathrm{D})(\mathrm{p}<.0001)$ and mean residual astigmatism magnitude $0.21 \pm 0.54 \mathrm{D}$ (range, 0.00 to $1.50 \mathrm{D})(\mathrm{p}<.001)$ ) and that $90 \%$ of eyes were within $\pm 0.50 \mathrm{D}$ of the attempted correction. For these cases, preoperative corneal coma aberration $(C[3, \pm 1])$ was $0.26 \pm 0.23 \mu \mathrm{m}$ RMS, corneal spherical aberration $(C[4,0])(\mathrm{SphAb})$ was $+0.28 \pm 0.15 \mu \mathrm{m}$, and corneal RMSho was $0.45 \pm 0.12 \mu \mathrm{m}$ RMS. Postoperatively, corneal coma magnitude changed to $0.30 \pm 0.25 \mu \mathrm{m}$ RMS ( $\mathrm{p}<.05$ ), corneal SphAb to $+0.38 \pm 0.24 \mu \mathrm{m}$ $(\mathrm{p}<.005)$, and corneal RMSho changed to $0.56 \pm 0.28 \mu \mathrm{m}$ RMS $(\mathrm{p}<.01)$. 

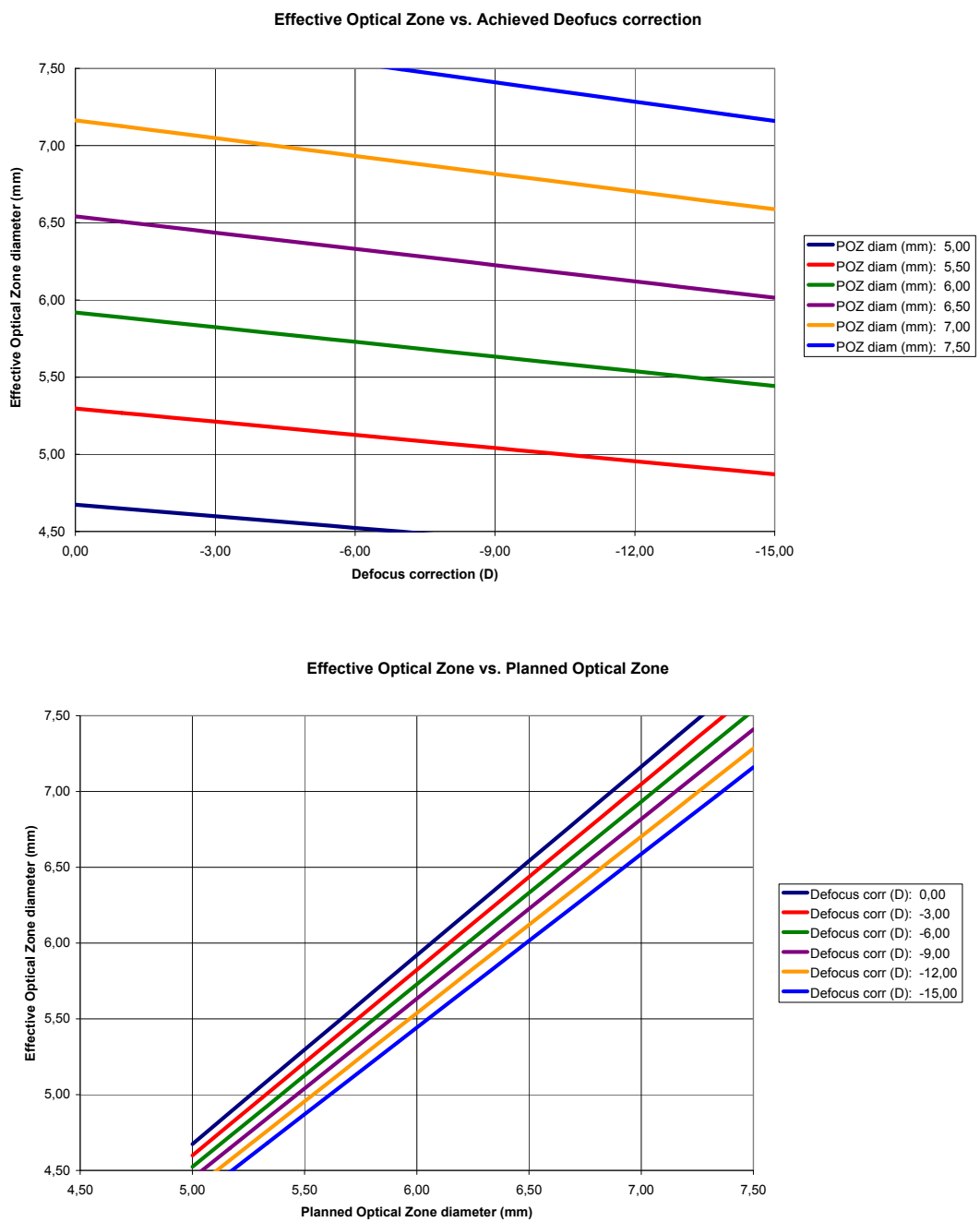

Fig. 5. Influence of the planned optical zone and defocus correction on the effective optical zone for myopia.

In hyperopia, in a similar case cohort of 20 consecutive patients, the Spherical equivalent and the cylinder were significantly reduced to subclinical values at six months postoperatively (mean residual defocus refraction was $-0.04 \pm 0.44 \mathrm{D}$ (range -1.00 to $+0.63 \mathrm{D}$ ) $(\mathrm{p}<.0001)$ and mean residual astigmatism magnitude $0.22 \pm 0.55 \mathrm{D}$ (range, 0.00 to $1.50 \mathrm{D}$ ) $(\mathrm{p}<.001)$ ) and $90 \%$ of eyes were within $\pm 0.50 \mathrm{D}$ of the attempted correction. Preoperative corneal coma aberration $(\mathrm{C}[3, \pm 1])$ was $0.27 \pm 0.24 \mu \mathrm{m}$ RMS, corneal spherical aberration $(\mathrm{C}[4,0])(\mathrm{SphAb})$ was $+0.29 \pm 0.16 \mu \mathrm{m}$, and corneal RMSho was $0.46 \pm 0.13 \mu \mathrm{m}$ RMS. Postoperatively, corneal coma magnitude changed to $0.34 \pm 0.26 \mu \mathrm{m}$ RMS $(\mathrm{p}<.05)$, corneal SphAb to $-0.01 \pm 0.25 \mu \mathrm{m}(\mathrm{p}<.005)$, and corneal RMSho changed to $0.64 \pm 0.29 \mu \mathrm{m}$ RMS $(\mathrm{p}<.01)$. 


\section{TransPRK}

In our own clinical experience, TransPRK in combination with corneal wavefront is the treatment of choice for retreatments after a radial keratotomy or corneal transplants ${ }^{46}$. At SEKAL, it is also used for haze, scarred corneal tissue and for keratoconus after crosslinking. In keratoconus, we aim at minimizing the ablation of tissue and smoothing the existing astigmatism.

The TransPRK technique makes sense in all cases where a difficult epithelial flap is expected or where the epithelium covers corneal irregularities of the stromal tissue.

Our approach is treating refracto-therapeutic problems by sequentially performing CornealWavefront guided aspheric ablation profiles followed by a defined epithelial thickness profile, without masking fluid, performed to take away the rest of epithelium that can be present in the center or in the periphery of the treated area. The new evolution of the SCHWIND AMARIS has implemented this technique (since September 2009) in a single step procedure. Thanks to this improvement the procedure is now faster and the amount of epithelial tissue is optimized to avoid the myopic like correction (about -0.75D). This new single-step approach is treating refracto-therapeutic problems by superimposing a defined epithelial thickness profile ( $\sim 55 \mu \mathrm{m}$ at the centre and $\sim 65 \mu \mathrm{m}$ at the periphery $4 \mathrm{~mm}$ radially from centre) with aspheric ablation profiles. The system analytically creates a single ablation volume, which is then discretised into laser pulses sorted spatially and temporally in a pseudo-random fashion. Further, there is a pseudo-sequentialization of the CornealWavefront guided and epithelial thickness profile components, but both components elapse without breaks.

The TransPRK (Transepithelial Photorefractive Keratectomy) with the SCHWIND AMARIS is an "all laser" version of surface treatments. Thereby the epithelium, which is the regenerative surface of the eye, is ablated by the laser system.

The TransPRK is the only surface treatment where the eye does not require contact with an instrument.

Furthermore, the epithelium is removed more precisely and more easily than through manual abrasion. Because the wound surface is smaller than, for example, with manual PRK, the healing process is shorter. Additionally, both the epithelium and the stroma are ablated in a single procedure. This shortens the overall treatment time significantly and minimises the risk of corneal dehydration.

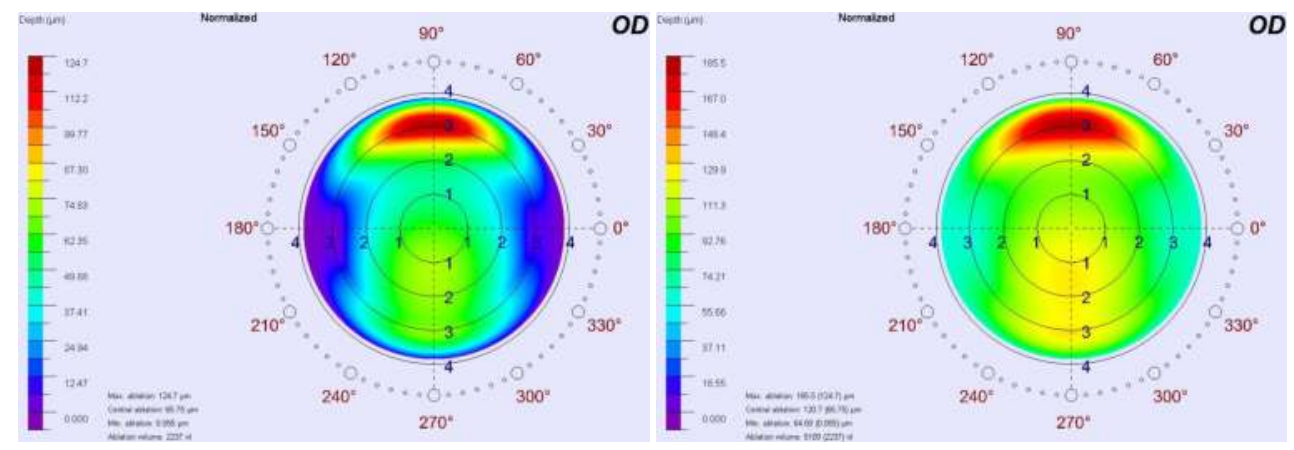

Fig. 6. Comparison between the PRK and TransPRK profiles of the same treatment. 
In our group of therapeutic patients, we had a remarkable decrease in corneal aberrations at 6-mm. Residual defocus averages about $-0.6 \mathrm{D}$, and residual cylinder about $0.9 \mathrm{D}$, with $71 \%$ within $1.0 \mathrm{D}$ of the target correction in defocus and astigmatism simultaneously. The mean decrease in astigmatism magnitude is $78 \%$, representing a moderate undercorrection of astigmatism. Analyzing our mean postoperative defocus component, no hyperopic shift was observed.

In our experience, the percentage of eyes with UCVA of $20 / 32$ or better is $60 \%$ and $20 \%$ achieve a UCVA of $20 / 20$ or better. $47 \%$ of the eyes gain two or more lines of BSCVA, with $23 \%$ of the eyes showing an increase of more than four lines (especially after penetrating keratoplasty).

Despite large defocus, astigmatism and HOA magnitudes, high order aberrations are drastically reduced after simultaneous aspheric Corneal-Wavefront guided TransPRK profiles using SCHWIND AMARIS system among eyes with refracto-therapeutic problems after radial keratotomy or keratoplasty. The correction of the most relevant aberrations correlates well with intended values.

\section{Corneal wavefront epi-LASEK}

The SCHWIND AMARIS offers different levels of aberrations control, in the form:

- $\quad$ Specifically designed ablation profiles

- Aberration-Free (our treatment of choice for primary treatments): Aspheric aberration neutral (Aberration-Free ${ }^{\mathrm{TM}}$ ) profiles are not based on the Munnerlyn proposed profiles, and go beyond that by adding some aspheric characteristics to balance the induction of spherical aberration, (prolateness optimization). The aberration neutral (AberrationFree ${ }^{\mathrm{TM}}$ ) profile is aspherical-based, including a multidynamic aspherical transition zone (depending on planned refraction and optical zone size), aberration and focus shift compensation due to tissue removal, pseudo-matrix based spot positioning (spot overlapping is a major parameter, and the spot spacing is small compared to the spot width and multiple spots overlap, all contributing to the ablation at each corneal location), enhanced compensation for the loss of efficiency, and intelligent thermal effect control; all based on theoretical equations validated with ablation models and clinical evaluations.

- Corneal Wavefront (our treatment of choice for secondary treatments): The treatment plan is developed using CW customized aspheric profiles based on corneal ray tracing. Using the Keratron Scout videokeratoscope, the topographical surface and corneal wavefront are analyzed (up to the seventh order). Considering a balanced-eye model (Q-Val -0.25) the departure of the measured corneal topography from the theoretically optimal corneal surface is calculated. Optical errors centered on the line of sight are described by the Zernike polynomials and the coefficients of the Optical Society of America standard. In corneal wavefront analysis, the type and size of any optical error on the anterior corneal surface are registered, thus allowing a very selective correction. The defects are corrected exactly at their origin - the anterior corneal surface. In this context, the precise localization of defects is crucial to successfully achieving optimal results in laser surgery. The corneal wavefront allows for a very precise diagnosis, thus providing an individual ablation of the cornea in order to obtain perfect results. Applying this treatment strategy, measurement does not require pupil dilation of the eye, so that the treatment zone is not limited by the pupil and accomodation does not 
influence the measuring results. Mention is made that in this way forcing a fixed asphericity quotient (Q) on the eyes through the treatment is avoided. Instead, this strategy employs a dynamic postoperative expected asphericity quotient.

- Ocular Wavefront (only sporadically used in our experience): The treatment plan is developed using OW customised aspheric profiles based on Hartmann-Shack sensing. The high-resolution Hartmann-Shack measurements (>800 points for a 7.0$\mathrm{mm}$ pupil) refer to the entire eye. Optical errors centered on the line-of-sight are described by the Zernike polynomials and the coefficients of the Optical Society of America standard.

\begin{tabular}{|c|c|c|c|}
\hline Aspherical ablation profile & $\begin{array}{c}\text { Aberration-free } \\
\text { Treatment }\end{array}$ & $\begin{array}{c}\text { Corneal } \\
\text { Wavefront } \\
\text { Treatment }\end{array}$ & $\begin{array}{c}\text { Ocular Wavefront } \\
\text { Treatment }\end{array}$ \\
\hline $\begin{array}{c}\text { Simultaneous correction of Sphere } \\
\text { + Cylinder }\end{array}$ & Yes & Yes & Yes \\
\hline $\begin{array}{c}\text { Correction of high order } \\
\text { aberrations }\end{array}$ & Preserved & Yes & Yes \\
\hline $\begin{array}{c}\text { Compensation by microkeratome } \\
\text { usually induced aberrations } \\
\text { (biomechanical effect) }\end{array}$ & Yes & Yes & Yes \\
\hline $\begin{array}{c}\text { Compensation of ablation induced } \\
\text { aberrations (biomechanical effect) }\end{array}$ & Yes & Yes & Yes \\
\hline $\begin{array}{c}\text { Compensation of energy loss of the } \\
\text { laser beam }\end{array}$ & Yes & Yes & Yes \\
\hline
\end{tabular}

Table 1. Level of detail available at AMARIS.

We apply corneal wavefront based profiles for all retreatments in order to eliminate (or at least reduce) higher order aberrations.

\section{Pathologic transPRK}

Refracto-therapeutic surgery with excimer laser has evolved from simple cylindric ablations ${ }^{47}$ to correct severe, disabling astigmatism after keratoplasty, although substantial regression limited its effectiveness, initially under the form of PRK ${ }^{48}$ and later on LASIK 49. The correction of classical ametropias (myopia and astigmatism) after penetrating keratoplasty using PRK 50 was less effective and less predictable than PRK for naturally occurring myopia and astigmatism, corneal haze and refractive regression were more prevalent. Refracto-therapeutic ablations evolved to the most sophisticated topographyguided customized corneal ablations for irregular corneal astigmatism after keratoplasty ${ }^{51,52}$. 


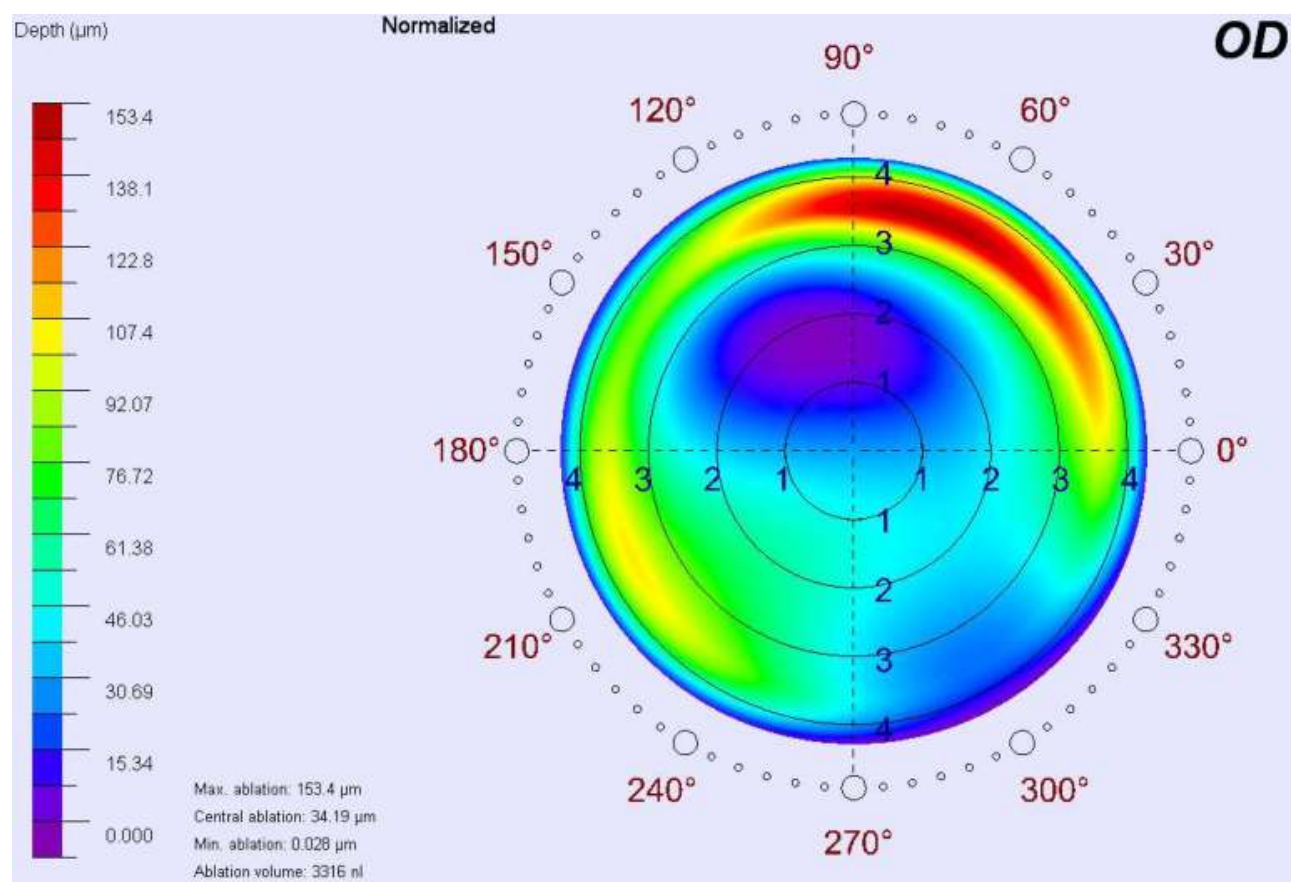

Fig. 7. CW guided Epi-LASEK ablation volume.

2-step procedures were proposed either in the form PTK + customized PRK or Flap + customized LASIK ${ }^{53}$ as well as wavefront-driven customised ablation patterns mostly using corneal topography-derived wavefront analyses ${ }^{54}$. Another proposal is the use of simultaneous customized transepithelial PRK + PTK 55 , which combines the refractive effect of the PRK with the therapeutic effect of a laser-assisted epithelium removal. A similar evolution can be observed in the resolution of residual myopia in eyes following radial keratotomies, with lower predictability ${ }^{56}$ using PRK associated with greater corneal haze and regression of refractive correction than in previously unoperated eyes, and encouraging early postoperative results of the correction by LASIK of a hyperopic shift after RK 57 . However, specific LASIK risks after RK exist in the form of uncontrolled shearing forces in lifting the corneal flap and extension of radial keratotomy wound dehiscence, which could lead to epithelial ingrowth and loss of best-corrected vision ${ }^{58}$.

Our approach is treating refracto-therapeutic problems by sequentially performing a Corneal-Wavefront guided aspheric ablation profiles followed by a defined epithelial thickness profile ${ }^{59}$ (60 to $70 \mu \mathrm{m}$ depth in our case) in the form of a PTK, without masking fluid, performed to take away the rest of epithelium that can be present in the center or in the periphery of the treated area. For both sequential ablations, the system analytically creates coresponding ablation volumes, which are then discretised into laser pulses sorted spatially and temporally in a pseudo-random fashion.

The advantage of this ablation profile is that aims reducing the corneal wave aberration (within Optical Zone) together with the sphere and cylinder components. PTK removes an epithelial thickness profile that could be considered a little myopic like treatment (about 


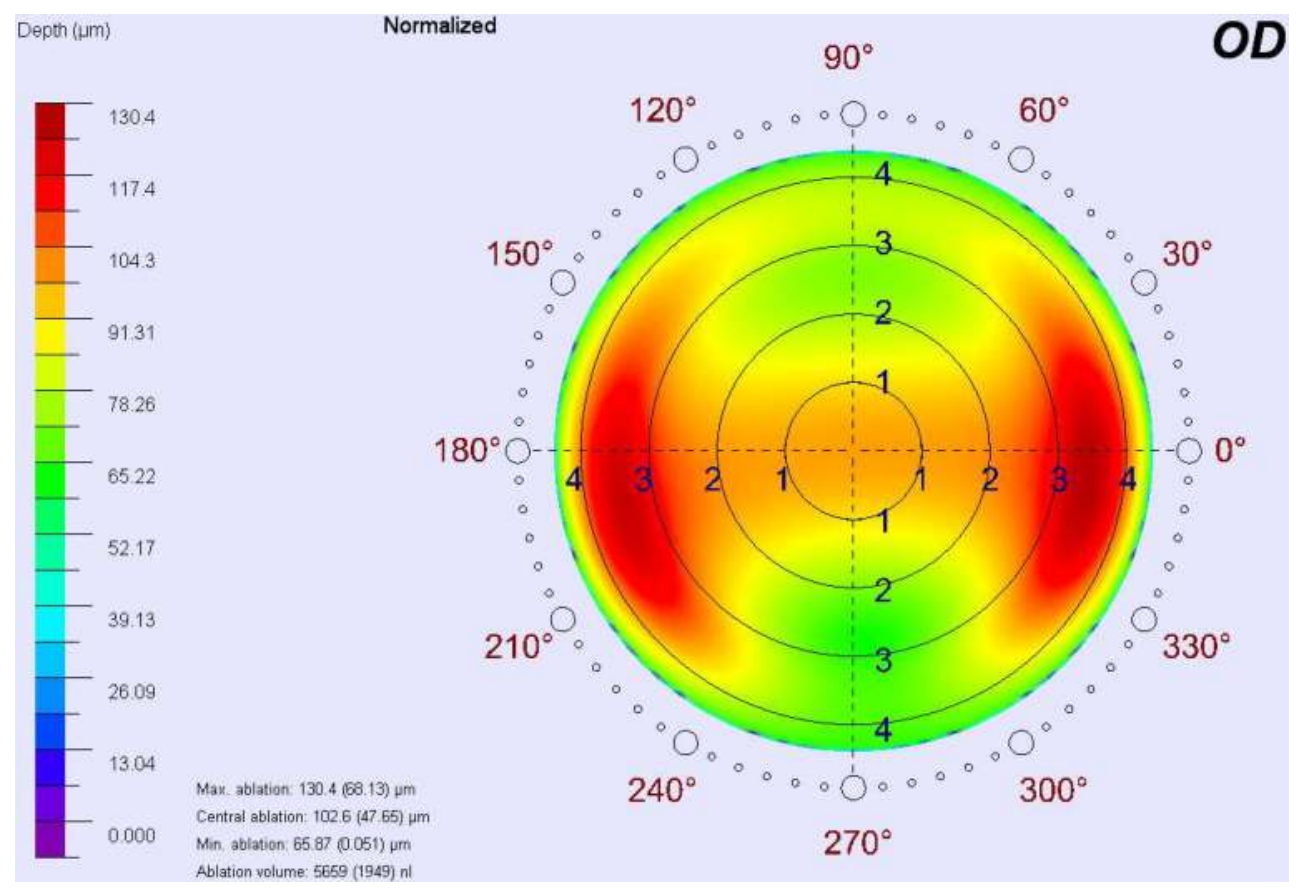

Fig. 8. CW guided TransPRK ablation volume.

$\left.1 \mathrm{D}^{60}\right)$, being epithelium thinner in the center $59,61,62$. We decided not to take into account this possible error because usually these corneas have a slight regression and this can lead to a compensating factor. We have thought to link the treatment directly over the epithelium as it acts as a smoothing agent. A rough stromal surface becomes smoother when epithelium re-grows but when we perform a topographical analysis we really assess the topography of the outer part (epithelium) and not the stromal surface.

We know epithelium is thicker in valleys and thinner in peaks and if we want a perfect result in these cases, we should perform a topographical analysis of the stromal surface, before ablation, but we know it is almost impossible due to the poor reflectivity.

The transepithelial approach allows a perfect correspondence between the topography and the cornea and the only error we can achieve is the difference in the photoablative rate between stroma and epithelial tissue ${ }^{63}$. This difference ( $20 \%$ higher in epithelium) is partly compensated at the AMARIS, and, anyway, negligible for small amount of tissue. The need to perform a PTK (with parallel layer) is in order to remove the possible rest of epithelium in the centre or in the periphery of the treatment. Usually this PTK has a depth of $60-70 \mu \mathrm{m}$ according to the ablation of the epithelium easy to check under microscope.

In our group of patients, we have remarkable decreases in corneal aberrations at 6-mm.

Analyzing our mean postoperative defocus component, no hyperopic shift was observed despite no nomogram adjustments or coupling effects were accounted for.

In our study, the percentage of eyes with UCVA of $20 / 32$ or better was $60 \%$ and $20 \%$ had a UCVA of 20/20 or better. No single eye had a loss even one line of BSCVA, and sixteen eyes had gained two or more lines of BSCVA $(p<.05), 8$ eyes $(23 \%)$ had an increase of more than 
four lines. Especially at the KP group, 14 of 18 treated eyes gained two or more lines of BSCVA after simultaneous aspheric CWg TransPRK + PTK with AMARIS.

As shown from the data presented, simultaneous aspheric Corneal-Wavefront guided TransPRK + PTK profiles using SCHWIND AMARIS system among eyes with refractotherapeutic problems after radial keratotomy or keratoplasty are safe and effective. This is an improvement relative to previous laser platforms, and may be related to the high-speed AMARIS system reduces variability from stromal hydration effects, which increase with time of treatment 64,65 .

Despite large defocus, astigmatism and HOA magnitudes, high order aberrations are drastically reduced after simultaneous aspheric Corneal-Wavefront guided TransPRK + PTK profiles using SCHWIND AMARIS system among eyes with refracto-therapeutic problems after radial keratotomy or keratoplasty. The correction of the most relevant aberrations correlates well with intended values. The refractive results in this clinical setting show a trend toward slight undercorrection in astigmatism, we believe that with some slight adjustment for astigmatic correction, the percentage of eyes within $\pm 0.50 \mathrm{D}$ of intended correction will increase significantly. The same applies for the difference observed between the rate of aberration correction. Although this small series of treated eyes does not allow for definitive conclusions or evidence-based statements, our preliminary results are promising.

In a previous study ${ }^{66}$ we have checked the stability of these corrections following RK and demonstrated that in three years, refraction and mean corneal power remained stable. We have seen that hyperopic shift following RK reaches a value and seems to stop at a certain time point. Our feeling is that probably the variation is partially due to an increased thickness of the cornea in the area of the incisions, as we have observed with a Scheimpflug camera, and partially due to an ectasia. The long term stability we have observed seems to claim for a major effect of the increased thickness as to explain the hyperopic shift. The reason of the increased thickness can be an augment in the hydration of the stroma.

As for corneal transplants, the problem is more complex since we know that astigmatism is a long term side effect and, for keratoconus, involves the inferior area of the cornea. We can suppose a massage effect of the upper lid that both in RK eyes and in transplant ones determines a bulging effect in the inferior area of the cornea. In both cases, when the defect is too high, it is not safe to approach with a laser treatment because we should ablate too much tissue weakening the structure. We must therefore take into account the thickness and the amount of tissue to remove before choosing a laser procedure. As a rule of thumb, we leave at least $300 \mu \mathrm{m}$ of untouched stroma.

Haze is not a problem anymore thanks to MMC and only one case (with traces) following transplant have shown this problem in our analysis.

We are aware that a laser treatment on an unstable cornea could lead to a dehiscence in future but we must balance the advantage of a fast and easy procedure with the possible (not certain risk) variation of the astigmatism in the future.

We think these cases have no other solutions apart a new corneal transplant so this approach can be considered safer and faster.

Particularly, a delayed regression may occur at least up to one year, when MMC is used. Despite these limitations, simultaneous aspheric CWg TransPRK + PTK ablation profiles with AMARIS are superior to other ablation profiles for the correction of refractotherapeutic problems after radial keratotomy or keratoplasty. 
In summary, simultaneous aspheric CWg TransPRK + PTK ablation profiles with AMARIS yield very good visual, optical, and refractive results for the correction of refractotherapeutic problems after radial keratotomy or keratoplasty. Preoperative astigmatisms are postoperatively reduced to subclinical values in the RK group and to moderate values in the KP group, with important reduction of High-Order-Aberrations (which influence contrast sensitivity). Simultaneous aspheric CWg TransPRK + PTK ablation profiles with AMARIS have, therefore, the potential to replace currently used algorithms for the correction of refracto-therapeutic problems after radial keratotomy or keratoplasty.

\section{References}

[1] Munnerlyn CR, Koons SJ, Marshall J. Photorefractive keratectomy: a technique for laser refractive surgery. J Cataract Refract Surg; 1988;14:46-52

[2] Uozato H, Guyton D. Centring corneal surgical procedures. Am J Ophthal 1987;103:26475

[3] Pop M, Payette Y. Photorefractive keratectomy versus laser in situ keratomileusis: a control-matched study. Ophthalmology. 2000; 107: 251-257.

[4] Hersh PS, Steinert RF, Brint SF; Summit PRK-LASIK Study Group. Photorefractive keratectomy versus laser in situ keratomileusis: a comparison of optical side effects. Ophthalmology. 2000; 107: 925-933.

[5] Maloney RK. Corneal topography and optical zone location in photorefractive keratectomy. Refract Corneal Surg 1990; 6: 363-371.

[6] Hersh PS, Schwartz-Goldstein BH; Summit Photorefractive Keratectomy Topography Study Group. Corneal topography of phase III excimer laser photorefractive keratectomy: characterization of clinical effects. Ophthalmology. 1995; 102: 963-978.

[7] O'Brart DPS, Gartry DS, Lohmann CP, Kerr Muir MG, Marshall J. Excimer laser photorefractive keratectomy for myopia: comparison of 4.00- and 5.00- millimeter ablation zones. J Refract Corneal Surg. 1994; 10: 87-94.

[8] Roberts CW, Koester CJ. Optical zone diameters for photorefractive corneal surgery. Invest Ophthalmol Vis Sci. 1993; 34: 2275-2281.

[9] Halliday BL. Refractive and visual results and patient satisfaction after excimer laser photorefractive keratectomy for myopia. Br J Ophthalmol. 1995; 79: 881-887.

[10] Moreno-Barriuso E, Lloves JM, Marcos S. Ocular Aberrations before and after myopic corneal refractive surgery: LASIK-induced changes measured with LASER ray tracing. Invest Ophthalmol Vis Sci 2001; 42:1396-1403

[11] Marcos S, Barbero S, Llorente L, Merayo J. Optical response to LASIK for myopia from total and corneal aberration measurements. Invest Ophthalmol Vis Sci. 2001; 42: 33493356.

[12] Liang J, Grimm B, Goelz S, Bille JF. Objective measurement of wave aberrations of the human eye with the use of a Hartmann-Shack wave-front sensor. J Opt Soc Am A Opt Image Sci Vis. 1994; 11: 1949-57

[13] Alio JL, Belda JI, Osman AA, Shalaby AM. Topography-guided laser in situ keratomileusis (TOPOLINK) to correct irregular astigmatism after previous refractive surgery. J Refract Surg; 2003;19:516-27. 
[14] Mrochen M, Kaemmerer M, Seiler T. Clinical results of wavefront-guided laser in situ keratomileusis 3 months after surgery. J Cataract Refract Surg. 2001;27:201-7.

[15] Salmon TO. Corneal contribution to the Wavefront aberration of the eye. PhD Dissertation; 1999: 70

[16] Mrochen M, Jankov M, Bueeler M, Seiler T. Correlation Between Corneal and Total Wavefront Aberrations in Myopic Eyes. J Refract Surg; 2003;19:104-112

[17] Mrochen M, Donetzky C,Wüllner C, Löffler J. Wavefront-optimized ablation profiles: Theoretical background. J Cataract Refract Surg; 2004;30:775-785

[18] Koller T, Iseli HP, Hafezi F, Mrochen M, Seiler T. Q-factor customized ablation profile for the correction of myopic astigmatism. J Cataract Refract Surg; 2006; 32:584-589

[19] Mastropasqua L, Nubile M, Ciancaglini M, Toto L, Ballone E. Prospective randomized comparison of wavefront-guided and conventional photorefractive keratectomy for myopia with the meditec MEL 70 laser. J Refract Surg. 2004; 20: 422-31

[20] Villegas EA, Alcón E, Artal P. Optical quality of the eye in subjects with normal and excellent visual acuity. Invest Ophthalmol Vis Sci; 2008; 49: 4688-96

[21] Marcos S, Cano D, Barbero S. Increase in corneal asphericity after standard LASIK for myopia is not inherent to the Munnerlyn algorithm. J Refract Surg; 2003; 19: S5926

[22] Mrochen M, Seiler T. Influence of Corneal Curvature on Calculation of Ablation Patterns used in photorefractive Laser Surgery. J Refract Surg; 2001;17:584-587

[23] Jiménez JR, Anera RG, Jiménez del Barco L, Hita E. Effect on laser-ablation algorithms of reflection losses and nonnormal incidence on the anterior cornea. Applied Physics Letters; 2002; 81: 1521-1523

[24] Jiménez JR, Anera RG, Jiménez del Barco L, Hita E, Pérez-Ocón F. Correlation factor for ablation agorithms used in corneal refractive surgery with gaussian-profile beams. Optics Express; 2005; 13: 336-343

[25] Nepomuceno RL, Boxer Wachler BS, Scruggs R. Functional optical zone after myopic LASIK as a function of ablation diameter. J Cataract Refract Surg. 2005; 31: 379384.

[26] Rojas MC, Manche EE. Comparison of videokeratographic functional optical zones in conductive keratoplasty and LASIK for hyperopia. J Refract Surg. 2003; 19: 333337.

[27] Reinstein DZ, Silverman RH, Sutton HF, Coleman DJ. Very highfrequency ultrasound corneal analysis identifies anatomic correlates of optical complications of lamellar refractive surgery: anatomic diagnosis in lamellar surgery. Ophthalmology. 1999; 106: 474-482.

[28] Dorronsoro C, Cano D, Merayo-Lloves J, Marcos S. Experiments on PMMA models to predict the impact of refractive surgery on corneal shape. Opt. Express; 2006; 14: 6142-6156

[29] Dupps WJ Jr, Roberts C. Effect of acute biomechanical changes on corneal curvature after photokeratectomy. J Refract Surg. 2001; 17: 658-669. 
[30] Wang Z, Chen J, Yang B. Posterior corneal surface topographic changes after LASIK are related to residual corneal bed thickness. Ophthalmology; 1999; 106: 406-9

[31] Binder PS. Analysis of ectasia after laser in situ keratomileusis: risk factors. J Cataract Refract Surg; 2007; 33: 1530-8

[32] Tabernero J, Klyce SD, Sarver EJ, Artal P. Functional optical zone of the cornea. Invest Ophthalmol Vis Sci. 2007; 48: 1053-60.

[33] Mok KH, Lee VW. Effect of optical zone ablation diameter on LASIK-induced higher order optical aberrations. J Refract Surg. 2005; 21: 141-143.

[34] Netto MV, Ambrosio R Jr, Wilson SE. Pupil size in refractive surgery candidates. J Refract Surg. 2004;20:337-342.

[35] Partal AE, Manche EE. Diameters of topographic optical zone and programmed ablation zone for laser in situ keratomileusis for myopia. J Refract Surg. 2003; 19: 528-33

[36] Qazi MA, Roberts CJ, Mahmoud AM, Pepose JS. Topographic and biomechanical differences between hyperopic and myopic laser in situ keratomileusis. J Cataract Refract Surg. 2005; 31: 48-60

[37] Seiler T, Reckmann W, Maloney RK. Effective spherical aberration of the cornea as a quantitative descriptor in corneal topography. J Cataract Refract Surg. 1993; 19: 155165.

[38] Kohnen T, Mahmoud K, Bühren J. Comparison of corneal higher-order aberrations induced by myopic and hyperopic LASIK. Ophthalmology. 2005; 112: 1692

[39] Qazi MA, Roberts CJ, Mahmoud AM, Pepose JS. Topographic and biomechanical differences between hyperopic and myopic laser in situ keratomileusis. J Cataract Refract Surg. 2005; 31: 48-60

[40] Laser epithelial keratomileusis for myopia. Camellin M. J Refract Surg. 2003; 19: 66670

[41] Epi-LASIK versus epi-LASEK. Camellin M, Wyler D. J Refract Surg. 2008; 24: S57-63

[42] J Refract Surg. 2008 May;24(5):462. What about LASEK? Camellin M.

[43] J Cataract Refract Surg. 2005 Sep;31(9):1719-21. Measurement of the spatial shift of the pupil center. Camellin M, Gambino F, Casaro S.

[44] J Refract Surg. 2010 May 19:1-12. doi: 10.3928/1081597X-20100428-03. [Epub ahead of print] Aspheric Optical Zones: The Effective Optical Zone with the SCHWIND AMARIS. Camellin M, Mosquera SA.

[45] J Refract Surg. 2004 Sep-Oct;20(5 Suppl):S693-8. Laser epithelial keratomileusis with mitomycin C: indications and limits. Camellin $\mathrm{M}$.

[46] Camellin M, Arba Mosquera S. Simultaneous aspheric wavefront-guided transepithelial photorefractive keratectomy and phototherapeutic keratectomy to correct aberrations and refractive errors after corneal surgery. J Cataract Refract Surg; 2010; 36: $1173-1180$

[47] Campos M, Hertzog L, Garbus J, Lee M, McDonnell PJ. Photorefractive keratectomy for severe postkeratoplasty astigmatism. Am J Ophthalmol. 1992; 114: 429-36

[48] Amm M, Duncker GI, Schröder E. Excimer laser correction of high astigmatism after keratoplasty. J Cataract Refract Surg. 1996; 22: 313-7 
[49] Arenas E, Maglione A. Laser in situ keratomileusis for astigmatism and myopia after penetrating keratoplasty. J Refract Surg. 1997; 13: 27-32

[50] Bilgihan K, Ozdek SC, Akata F, Hasanreisoğlu B. Photorefractive keratectomy for postpenetrating keratoplasty myopia and astigmatism. J Cataract Refract Surg. 2000; 26: 1590-5.

[51] Hjortdal JØ, Ehlers N. Treatment of post-keratoplasty astigmatism by topography supported customized laser ablation. Acta Ophthalmol Scand. 2001; 79: 376-80.

[52] Alessio G, Boscia F, La Tegola MG, Sborgia C. Corneal interactive programmed topographic ablation customized photorefractive keratectomy for correction of postkeratoplasty astigmatism. Ophthalmology. 2001; 108: 2029-37.

[53] Alió JL, Javaloy J, Osman AA, Galvis V, Tello A, Haroun HE. Laser in situ keratomileusis to correct post-keratoplasty astigmatism; 1-step versus 2-step procedure. J Cataract Refract Surg. 2004; 30: 2303-10.

[54] Rajan MS, O'Brart DP, Patel P, Falcon MG, Marshall J. Topography-guided customized laser-assisted subepithelial keratectomy for the treatment of postkeratoplasty astigmatism. J Cataract Refract Surg. 2006; 32: 949-57

[55] Pedrotti E, Sbabo A, Marchini G. Customized transepithelial photorefractive keratectomy for iatrogenic ametropia after penetrating or deep lamellar keratoplasty. J Cataract Refract Surg. 2006; 32: 1288-91

[56] Burnstein Y, Hersh PS. Photorefractive keratectomy following radial keratotomy. J Refract Surg. 1996; 12: 163-70

[57] Lipshitz I, Man O, Shemesh G, Lazar M, Loewenstein A. Laser in situ keratomileusis to correct hyperopic shift after radial keratotomy. J Cataract Refract Surg. 2001; 27: 2736

[58] Chung MS, Pepose JS, Manche EE. Management of the corneal flap in laser in situ keratomileusis after previous radial keratotomy. Am J Ophthalmol. 2001; 132: 252-3

[59] Reinstein DZ, Archer TJ, Gobbe M, Silverman RH, Coleman DJ. Epithelial thickness in the normal cornea: three-dimensional display with Artemis very high-frequency digital ultrasound. J Refract Surg. 2008; 24: 571-81

[60] Patel S, Marshall J, Fitzke FW. Refractive index of the human corneal epithelium and stroma. J Refract Surg 1995; 11: 100-105

[61] Simon G, Legeais JM, Parel JM. Optical power of the corneal epithelium. J Fr Ophtalmol 1993; 16: 41-47

[62] Legeais JM, Mayer F, Saragoussi JJ, Abenhaim A, Renard G. The optical power of the corneal epithelium. In vivo evaluation. J Fr Ophtalmol 1997; 20: 207-212

[63] Seiler T, Kriegerowski M, Schnoy N, Bende T. Ablation rate of human corneal epithelium and Bowman's layer with the excimer laser $(193 \mathrm{~nm})$. Refract Corneal Surg 1990; 6: 99-102

[64] Kim WS, Jo JM. Corneal hydration affects ablation during LASIK surgery. Cornea. 2001;20:394-397

[65] Dougherty PJ, Wellish KL, Maloney RK. Excimer laser ablation rate and corneal hydration. Am J Ophthalmol. 1994; 118: 169-176. 
[66] Camellin M. Lasek \& Asa History Technique Long-term Results. Fabiano Editore, Canelli 2006: 277 


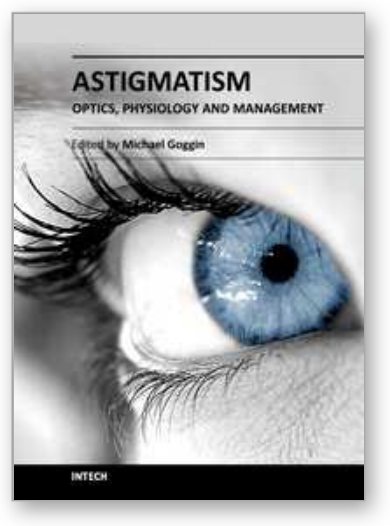

\author{
Astigmatism - Optics, Physiology and Management \\ Edited by Dr. Michael Goggin
}

ISBN 978-953-51-0230-4

Hard cover, 308 pages

Publisher InTech

Published online 29, February, 2012

Published in print edition February, 2012

This book explores the development, optics and physiology of astigmatism and places this knowledge in the context of modern management of this aspect of refractive error. It is written by, and aimed at, the astigmatism practitioner to assist in understanding astigmatism and its amelioration by optical and surgical techniques. It also addresses the integration of astigmatism management into the surgical approach to cataract and corneal disease including corneal transplantation.

\title{
How to reference
}

In order to correctly reference this scholarly work, feel free to copy and paste the following:

Massimo Camellin and Samuel Arba-Mosquera (2012). Aspheric Refractive Correction of Irregular Astimatism, Astigmatism - Optics, Physiology and Management, Dr. Michael Goggin (Ed.), ISBN: 978-953-51-0230-4, InTech, Available from: http://www.intechopen.com/books/astigmatism-optics-physiology-andmanagement/aspheric-refractive-correction-of-irregular-astimatism

\section{INTECH}

open science | open minds

\author{
InTech Europe \\ University Campus STeP Ri \\ Slavka Krautzeka 83/A \\ 51000 Rijeka, Croatia \\ Phone: +385 (51) 770447 \\ Fax: +385 (51) 686166 \\ www.intechopen.com
}

\author{
InTech China \\ Unit 405, Office Block, Hotel Equatorial Shanghai \\ No.65, Yan An Road (West), Shanghai, 200040, China \\ 中国上海市延安西路65号上海国际贵都大饭店办公楼 405 单元 \\ Phone: +86-21-62489820 \\ Fax: $+86-21-62489821$
}


(C) 2012 The Author(s). Licensee IntechOpen. This is an open access article distributed under the terms of the Creative Commons Attribution 3.0 License, which permits unrestricted use, distribution, and reproduction in any medium, provided the original work is properly cited. 